\title{
Valorization of Spent Coffee by Caffeine Extraction Using Aqueous Solutions of Cholinium-Based Ionic Liquids
}

\author{
Ana M. Ferreira (D), Hugo M. D. Gomes, João A. P. Coutinho (D) and Mara G. Freire *(D) \\ CICECO-Aveiro Institute of Materials, Department of Chemistry, University of Aveiro, 3810-193 Aveiro, Portugal; \\ ana.conceicao@ua.pt (A.M.F.); hugogomes@ua.pt (H.M.D.G.); jcoutinho@ua.pt (J.A.P.C.) \\ * Correspondence: maragfreire@ua.pt
}

\begin{abstract}
Spent coffee grounds (SCGs) are a waste product with no relevant commercial value. However, SCGs are rich in extractable compounds with biological activity. To add value to this coffee byproduct, water and aqueous solutions of cholinium-based ionic liquids (ILs) were studied to extract caffeine from SCGs. In general, all IL aqueous solutions lead to higher extraction efficiencies of caffeine than pure water, with aqueous solutions of cholinium bicarbonate being the most efficient. A factorial planning was applied to optimize operational conditions. Aqueous solutions of cholinium bicarbonate, at a temperature of $80^{\circ} \mathrm{C}$ for $30 \mathrm{~min}$ of extraction, a biomass-solvent weight ratio of 0.05 and at an IL concentration of $1.5 \mathrm{M}$, made it possible to extract $3.29 \mathrm{wt} \%$ of caffeine (against $1.50 \mathrm{wt} \%$ obtained at the best conditions obtained with pure water). Furthermore, to improve the sustainability of the process, the same IL aqueous solution was consecutively applied to extract caffeine from six samples of fresh biomass, where an increase in the extraction yield from 3.29 to $13.10 \mathrm{wt} \%$ was achieved. Finally, the cholinium bicarbonate was converted to cholinium chloride by titration with hydrochloric acid envisioning the direct application of the IL-caffeine extract in food, cosmetic and nutraceutical products. The results obtained prove that aqueous solutions of cholinium-based ILs are improved solvents for the extraction of caffeine from SCGs, paving the way for their use in the valorization of other waste rich in high-value compounds.
\end{abstract}

H.M.D.; Coutinho, J.A.P.; Freire, M.G. Valorization of Spent Coffee by Caffeine Extraction Using Aqueous Solutions of Cholinium-Based Ionic Liquids. Sustainability 2021, 13, 7509. https://doi.org/10.3390/su13137509

Academic Editor: Matthew Jones

Received: 23 May 2021

Accepted: 30 June 2021

Published: 5 July 2021

Publisher's Note: MDPI stays neutral with regard to jurisdictional claims in published maps and institutional affiliations.

Copyright: (c) 2021 by the authors. Licensee MDPI, Basel, Switzerland. This article is an open access article distributed under the terms and conditions of the Creative Commons Attribution (CC BY) license (https:// creativecommons.org/licenses/by/ $4.0 /)$.

Keywords: solid-liquid extraction; ionic liquids; waste food; spent coffee; alkaloids; caffeine; factorial planning; process optimization

\section{Introduction}

Spent coffee grounds (SCGs) are the most abundant coffee by-product, being generated in coffee beverage preparation and instant coffee manufacturing, with a production of 6 million tons per year [1]. However, SCGs are not fully used in terms of valorization, since these residues are either burned for energy production or used as fertilizers [2]. However, this abundant resource is rich in valuable compounds, such as essential oils, tannins and polyphenols [3], as well as in caffeine [4]. These compounds have relevant antioxidant, anti-inflammatory radical scavenger, and antimicrobial properties $[5,6]$, and could be used in the food, dietary, pharmaceutical and agrochemical industries [7]. Moreover, caffeinecontaining drinks are very popular worldwide, with the Food and Drug Administration (FDA) regulating that any added caffeine must be labelled on human consumption products due to possible adulteration and health concerns [8]. Another worthy example is the current controversy on the consumption/use of natural versus synthetic enriched products [9]. Human consumers tend to prefer natural added-value compounds, as is the case of caffeine [9]; therefore, their extraction from natural sources has gained high importance in the past years $[10,11]$. Furthermore, it is expected that the Global Caffeine Market will surpass US\$23,219 Million by 2027 [12].

Conventional extraction processes of high-value compounds from biomass or waste may present several drawbacks, such as low efficiency and non-selectivity, being timeconsuming, requiring high energetic inputs, and leading to possible degradation of the 
target compounds [13]. Traditional methods tend to use volatile organic solvents in the extraction and separation steps, leading to safety and environmental concerns and thus preventing the targeted high-value chemicals from being used for human consumption $[13,14]$. The extraction of caffeine from biomass is typically carried out with supercritical $\mathrm{CO}_{2}$ [15], which, although selective and efficient, requires a high initial investment on equipment, or by applying volatile organic solvents, such as chloroform, methylene chloride, dichloromethane, ethanol, $n$-hexane and others [16,17].

With a view to more sustainable and selective processes for the extraction of caffeine from biomass, deep eutectic solvents (DES) and ionic liquids (ILs), as well as their aqueous solutions, have been investigated as alternative solvents. Cai et al. [18] obtained a caffeine extraction yield of $2.7 \mathrm{wt} \%$ from Chinese dark tea, using the DES formed by cholinium chloride-lactic acid ([Ch]Cl-LA) as the extraction solvent under the optimized conditions. On the other hand, Cláudio et al. [19] investigated the extraction of caffeine from Paullinia cupana (guarana seeds, Sapindaceae) using aqueous solutions of a series of imidazolium-, pyrrolidinium-, and ammonium-based ILs. At the optimal conditions, aqueous solutions of 1-butyl-3-methylimidazolium chloride, $\left[\mathrm{C}_{4} \mathrm{C}_{1} \mathrm{im}\right] \mathrm{Cl}$, were found to be the best solvent, with extraction yields of up to $9 \mathrm{wt} \%$, compared with $4 \mathrm{wt} \%$ obtained by soxhlet extraction using methylene chloride [19]. Other alkaloids have been extracted from vegetable biomass using ILs aqueous solutions, namely glaucine from Glaucium flavum Cr. (Papaveraceae) $[20,21]$, and galantamine, narwedine and ungiminorine from the aerial parts of Leucojum aestivum L. (Amaryllidaceae) [22]. In all these works, IL aqueous solutions were described as being more efficient and selective solvents than the volatile organic solvents typically used. In general, imidazolium-based ILs, combined with chloride, bromide, acetate, dicyanamide and tetrafluoroborate anions, have been the preferential choice in these extractions. However, and although it depends on the cation-anion combinations and their chemical structure, cost, toxicity and biodegradability concerns have been raised with imidazolium-based ILs paired with some of these anions [23,24]. Thus, there is still a need to identify more benign, cost-effective, and sustainable ILs for the extraction of high-value compounds from biomass.

Cholinium-based ILs have emerged as bio-derived ILs, and if properly designed can display attractive biocompatible and biodegradable features [25]. Their biocompatible nature is usually ascribed to their similar chemical structure to the water-soluble essential nutrient cholinium chloride (also known as vitamin B4), which is found in food obtained from vegetable or animal sources and supports several biological functions [26,27]. The cholinium cation has been combined with a wide variety of organic or inorganic anions, producing ILs with different properties [28-30]. In the field of biomass extractions, Ribeiro et al. [31] applied aqueous solutions of cholinium-based ILs as potential alternatives to imidazolium-based counterparts for the extraction of polyphenols and saponins from the leaves and aerial parts of Ilex paraguariensis (mate) and Camellia sinensis (tea). The authors concluded that $[\mathrm{Ch}] \mathrm{Cl}$ was the best solvent option for the extraction of saponins and phenolic compounds, either from mate or tea [31]. Recently, cholinium-based ILs were studied to simultaneously extract and isolate antioxidants and carbohydrates from food waste [29]. Despite all promising achievements, there is still a long path to take advantage of all the potential of more biocompatible ILs as alternative solvents to extract high-value compounds from biomass.

In this work, aqueous solutions of cholinium-based ILs were investigated as alternative solvents for extracting caffeine from SCGs. Factorial planning and optimization of the operating conditions (extraction time, temperature, biomass-solvent ratio and IL concentration) were applied to pure water and to the best IL aqueous solution identified to improve the extraction yield of caffeine. Both solvent and biomass reuse have also been investigated. Soxhlet extraction of caffeine from biomass was carried out using volatile organic solvents (petroleum ether, dichloromethane and ethanol) for comparison purposes. Finally, the best IL aqueous solution for the extraction of caffeine (cholinium bicarbonate, which among the studied ILs was the one with the lowest ecotoxicity [32]), was titrated 
with hydrochloric acid to obtain an extract rich in caffeine and cholinium chloride. Cholinium chloride is a compound naturally present in vegetable or animal food sources [33], making it possible to envision the direct application of the obtained SCG extracts in food, cosmetic and nutraceutical products.

\section{Materials and Methods}

\subsection{Materials}

SCGs were supplied by the Cafeteria of the Chemistry Department of the University of Aveiro, in Portugal. Samples were dried until constant weight ( $\approx$ for 6 days at $\left.100{ }^{\circ} \mathrm{C}\right)$, revealing an initial humidity content of $(59.5 \pm 2.5) \mathrm{wt} \%$. After the drying step, SCGs with particles diameter $<0.4 \mathrm{~mm}$ were isolated and used.

The ILs studied were cholinium ((2-hydroxyethyl)trimethylammonium) chloride ([Ch]Cl; $99 \mathrm{wt} \%$ pure), cholinium acetate ([Ch][Act]; $98 \mathrm{wt} \%$ pure), cholinium propanoate, ([Ch][Prop]; $>98 \mathrm{wt} \%$ pure), cholinium butanoate ([Ch][But]; $>98 \mathrm{wt} \%$ pure), cholinium dihydrogen phosphate ([Ch][DHP]; $99 \mathrm{wt} \%$ pure), cholinium dihydrogen citrate ([Ch][DHC]; $98 \mathrm{wt} \%$ pure), and cholinium bicarbonate ([Ch][Bic]; 80\% in water). [Ch][Act] was purchased from Iolitec, whereas the remaining carboxylate-based ILs were synthetized in our laboratory according to previously described protocols [34,35]. The remaining ILs were acquired from Sigma-Aldrich. With the exception of [Ch][Bic], all ILs were purified and dried for a minimum of $24 \mathrm{~h}$ at constant agitation, at moderate temperature $\left(\approx 60{ }^{\circ} \mathrm{C}\right)$ and under vacuum to reduce their volatile impurities to negligible values. After this step, the purity of each IL was confirmed by ${ }^{1} \mathrm{H}$ and ${ }^{13} \mathrm{C}$ NMR spectra. The chemical structures of the investigated ILs are depicted in Figure 1.<smiles>C[N+](C)(C)CCO</smiles>

(a)<smiles>CCCC(=O)O</smiles>

(d)<smiles>CC(=O)[O-]</smiles>

(b)<smiles>CCC(=O)[O-]</smiles>

(c)<smiles>C[N+](C)(C)CCO</smiles><smiles>C[N+](C)(C)CCO</smiles>

(f)<smiles>Cn1c(=O)c2c(ncn2C)n(C)c1=O</smiles>

(h)

Figure 1. Chemical structures of the ILs investigated (a) [Ch]Cl, (b) [Ch][Act], (c) [Ch][Prop], (d) [Ch][But], (e) [Ch][DHP], (f) [Ch][Bic] and (g) [Ch][DHC]; and of (h) caffeine.

The soxhlet extraction of caffeine was carried out using the organic volatile solvents ethanol, dichloromethane and petroleum ether, purchased from Sigma-Aldrich, BDH Prolabo and Carlo Erba, respectively, with $99.9 \%$ of purity. The water employed was ultra-pure water, double distilled, passed by a reverse osmosis system and further treated with a Milli-Q plus 185 water purification equipment. The high-purity caffeine, used as a standard in the calibration curves, was obtained from Marsing \& Co. Ltd. (Lanseria, 
South Africa), with a nominal purity $\geq 98.5 \mathrm{wt} \%$. Finally, the conversion of cholinium bicarbonate into cholinium chloride was carried using hydrochloric acid $(\mathrm{HCl})$, purchased from Sigma-Aldrich, with $37 \%$ in aqueous solution.

\subsection{Caffeine Extraction}

All ILs aqueous solutions were prepared gravimetrically within $10^{-4} \mathrm{~g}$ (using an analytical balance Mettler Toledo Excelence-XS205 Dual Range). Mixtures of specific amounts of SCGs and ILs aqueous solutions or water were prepared by weight in sealed glass vials. Several concentrations of ILs and different solid-liquid (biomass-solvent) ratios, times of extraction and temperatures were investigated to improve caffeine extraction yield according to the surface response methodology described below.

Extractions were carried out using commercial Carousel Radleys Tech equipment to stir and maintain the temperature within $\pm 0.5^{\circ} \mathrm{C}$. In all experiments, the stirring was kept at $300 \mathrm{rpm}$. After extraction, the overall solution was filtered under vacuum using $0.45 \mu \mathrm{m}$ cellulose membrane. After filtration, caffeine in the liquid solution was quantified through UV-spectroscopy, using a SHIMADZU UV-1700, Pharma-Spec Spectrometer, at a wavelength of $274 \mathrm{~nm}$ using a calibration curve previously established for caffeine. The chemical structure of caffeine is given in Figure 1. The effect of each IL on the quantification technique was evaluated, and it was found to be of no major influence when taking into account the dilutions carried out. At least three individual experiments were performed in order to determine the average in the yield of caffeine extracted, as well as the respective standard deviations. The percentage extraction yield of caffeine (caffeine yield ( $w t \%)$ ) corresponds to the weight of caffeine present in the extract divided by the total weight of dried SCGs.

Soxhlet extractions with several organic solvents at a solid-liquid ratio of 0.05 (10 g of biomass and $200 \mathrm{~mL}$ of solvent) were conducted for $7 \mathrm{~h}$ (420 min). For the UV-spectroscopy quantification, additional calibration curves were established in the different solvents, being caffeine quantified at $\lambda=274 \mathrm{~nm}$.

\subsection{Optimization of the Operational Conditions-Surface Response Methodology}

A $2^{3}$ factorial planning was used to optimize the amount of extracted caffeine from SCGs and identify the most significant parameters and their interactions. Factorial planning allows the simultaneous analysis of various factors. In the $2^{k}$ factorial planning, there are $k$ factors that can contribute to a different response, and data are treated according to a second-order polynomial equation, as described by Equation (1):

$$
y=\beta_{0}+\sum_{i} \beta_{i} X_{i+} \sum_{i} \beta_{i i} X_{i}^{2} \sum_{i<j} \beta_{i j} X_{i} X_{j}
$$

where $y$ is the response variable and $\beta_{0}, \beta_{i}, \beta_{i i}$ and $\beta_{i j}$ are the adjusted coefficients for the intercept, linear, quadratic and interaction terms, respectively, and $\chi_{i}$ and $\chi_{j}$ are independent variables. This mathematical model allows the drawing of surface response curves and through their analysis the optimal conditions can be determined. The factorial planning is defined by the central point (zero level), the factorial points ( 1 and -1 , level one) and the axial points (level $\alpha$ ). The central point and the axial points are defined by their use, depending on the purpose of the work. The axial points are encoded at a distance $\alpha$ from the central point, as given by Equation (2):

$$
\alpha=\left(2^{k}\right)^{\frac{1}{4}}
$$

The $2^{3}$ factorial planning used is provided in the Supplementary Materials (Tables S1-S3).

The parameters extraction time, temperature, solid-liquid ratio were considered for water, whereas for IL aqueous solutions the parameters temperature, solid-liquid ratio and IL concentration were used. The obtained results were statistically analyzed with a confidence level of $95 \%$. Student's t-test was used to check the statistical significance of 
the adjusted data. The model's adequacy was determined by evaluating the lack of fit, the regression coefficient $\left(\mathrm{r}^{2}\right)$ and the F-value obtained from the analysis of variance (ANOVA) that was generated. Three-dimensional surface response plots were generated by varying the experimental range variables and holding the other factors constant at the central point. Statsoft Statistica 8.0@ software was used for all statistical analysis, and Matlab R2010a, The MathWorks, was used for representing the response surfaces and contour plots.

To evaluate the maximum amount of caffeine present in the biomass, fresh aqueous solutions of [Ch][Bic] at $1.5 \mathrm{M}$ (the best identified solvent, for three cycles of extraction) were applied to the same biomass sample up to exhaustion, at the optimized operational conditions (solid-liquid ratio of 0.05 during $30 \mathrm{~min}$, at $80^{\circ} \mathrm{C}$ ). After each extraction, the solid-liquid mixture was filtered, and a new IL aqueous solution was added to the same biomass sample. On the other hand, with the goal of developing a more sustainable extraction process, the reuse of the solvent was addressed by applying six successive cycles of extraction using the same IL aqueous solution, also under the optimum operational conditions (solid-liquid ratio of 0.05 during $30 \mathrm{~min}$, at $80^{\circ} \mathrm{C}$ ). After each extraction cycle, the solid-liquid mixture was filtered, and a new biomass sample was added to the same IL aqueous solution.

With the aim of converting [Ch][Bic] into a compound naturally present in vegetable or animal food sources, namely [Ch] $\mathrm{Cl}$ [30], the extracted solution rich in caffeine (after six successive extractions) was titrated with $\mathrm{HCl}$ at $2 \mathrm{M}$, with simultaneous carbon dioxide $\left(\mathrm{CO}_{2}\right)$ release. The extract, before and after the addition of $\mathrm{HCl}$, was analyzed by ${ }^{13} \mathrm{C} \mathrm{NMR}$ spectra and FTIR to address the conversion of [Ch][Bic] into [Ch]Cl.

\section{Results and Discussion}

\subsection{Optimization of the Operating Conditions Using Water}

With the goal of optimizing the operating conditions to obtain high extraction yields of caffeine from SCGs, a response surface methodology (RSM) was applied with water as the solvent of extraction. This type of strategy allows the exploration of the relationship between the response (yield of caffeine) and the independent variables that can influence the extraction. An initial $2^{3}$ factorial planning (three factors and two levels, presented in the Supplementary Materials, Table S1) was performed using pure water as solvent to optimize the operationing conditions (temperature $(\mathrm{T})$, solid-liquid (biomass-solvent) ratio $\left(\mathrm{S} / \mathrm{L}\right.$ ratio) and extraction time $(\mathrm{t})$ ). The central point used in the planning was set at $70{ }^{\circ} \mathrm{C}$, a solid-liquid ratio of 1:10 and a time of $30 \mathrm{~min}$ (all conditions used for the extraction of caffeine are presented in the Supplementary Materials, Table S2). The results obtained were analyzed statistically with a confidence level of $95 \%$, showing a $r^{2}$ of 0.904 and an average relative deviation between the experimental and the predicted values of ca. $0.30 \%$, supporting the good description of the experimental results by the statistical model.

According to the statistical analysis (Supplementary Materials, Table S4, Figures S1 and S2) and the data depicted in Figure 2 it is evident that the caffeine extraction yield improves with an increase in temperature, with a decrease in the solid-liquid ratio and extraction times longer than $30 \mathrm{~min}$. However, the Pareto chart analysis shows that the extraction time is not a parameter with a significant effect on caffeine extraction yield (Supplementary Materials, Figure S1), contrary to the temperature and solid-liquid ratio. From the optimization approach, and using water as the solvent, it can be concluded that the optimum conditions required for the extraction of caffeine are: temperature at $85^{\circ} \mathrm{C}$, solid-liquid ratio of 0.1 and $30 \mathrm{~min}$ of extraction. Under these optimum operating conditions, the maximum extraction yield of caffeine using pure water was $1.50 \mathrm{wt} \%$. 
(a)

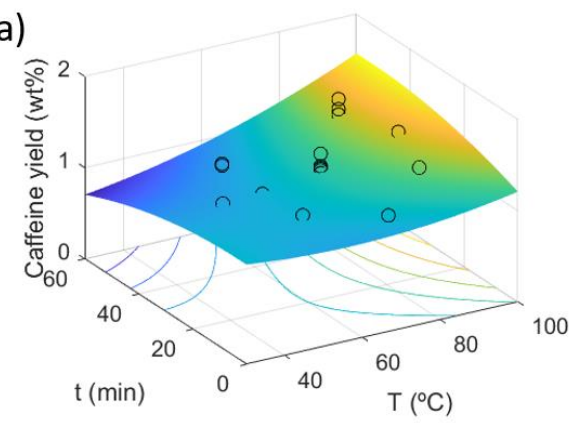

(b)

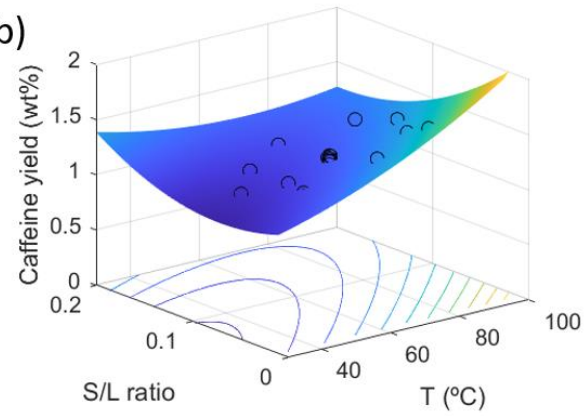

(c)

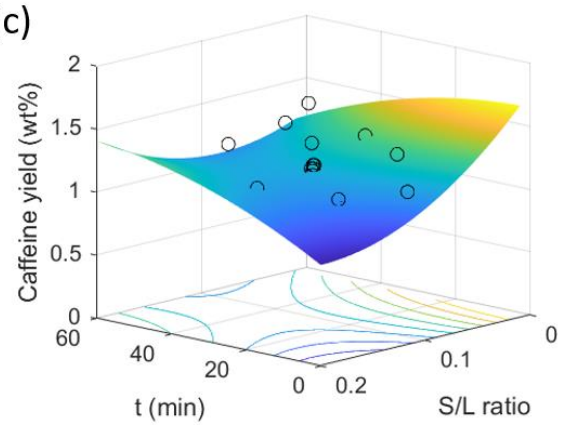

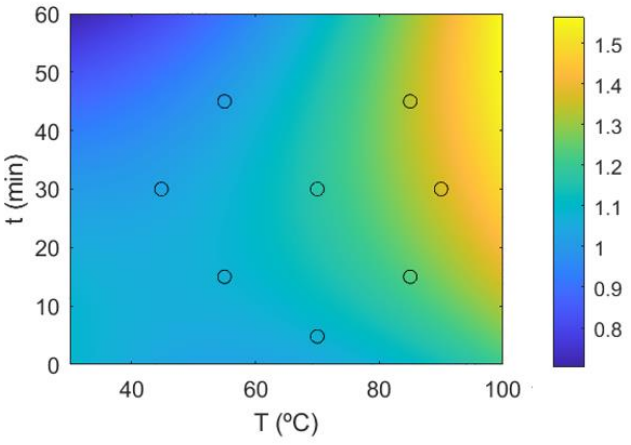
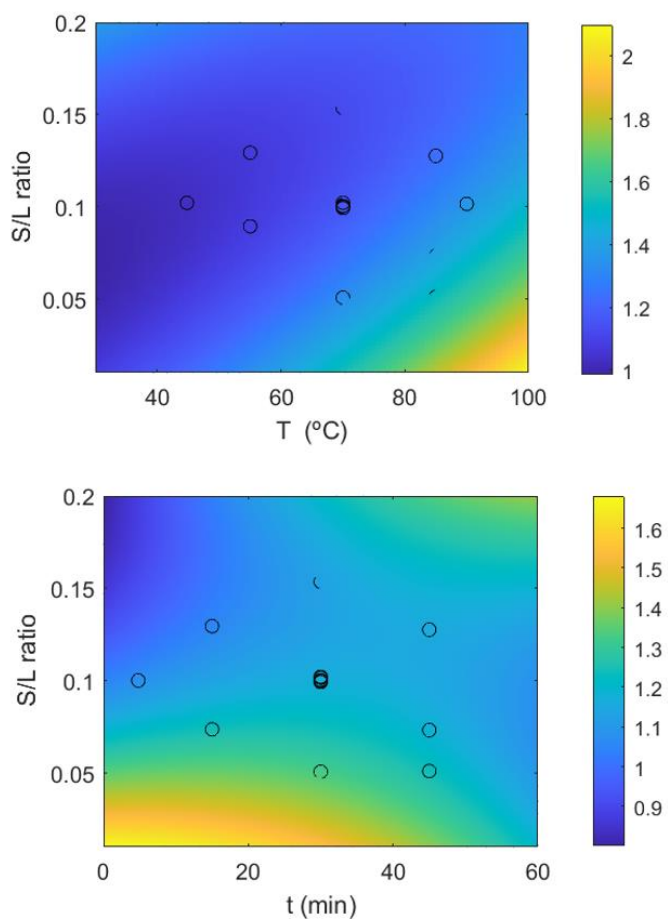

Figure 2. Response surface plots (left) and contour plots (right) on the caffeine yield from SCGs using water as the solvent with the combined effects of (a) temperature and time; (b) temperature and solid-liquid ratio; and (c) time and solid-liquid ratio.

\subsection{Effect of the Ionic Liquid Chemical Structure}

To improve the extraction yields of caffeine from SCGs, several aqueous solutions of cholinium-based ILs were investigated. In this screening of the best IL chemical structure able to provide high extraction yields, aqueous solutions of [Ch]Cl, [Ch][Act], [Ch][Prop], [Ch][But], [Ch][DHP], [Ch][DHC] and [Ch][Bic] at $2 \mathrm{M}$ were tested, the results of which are depicted in Figure 3. The constant extraction conditions used were chosen according to the results previously discussed on the $2^{3}$ factorial planning with water, in which statistical analysis showed that time is not a significant variable for caffeine extraction. Extractions were carried out with the time fixed at $30 \mathrm{~min}$, and at the temperature of $85^{\circ} \mathrm{C}$ and at a solid-liquid ratio of 0.1 as the best extraction conditions identified using water as solvent. 


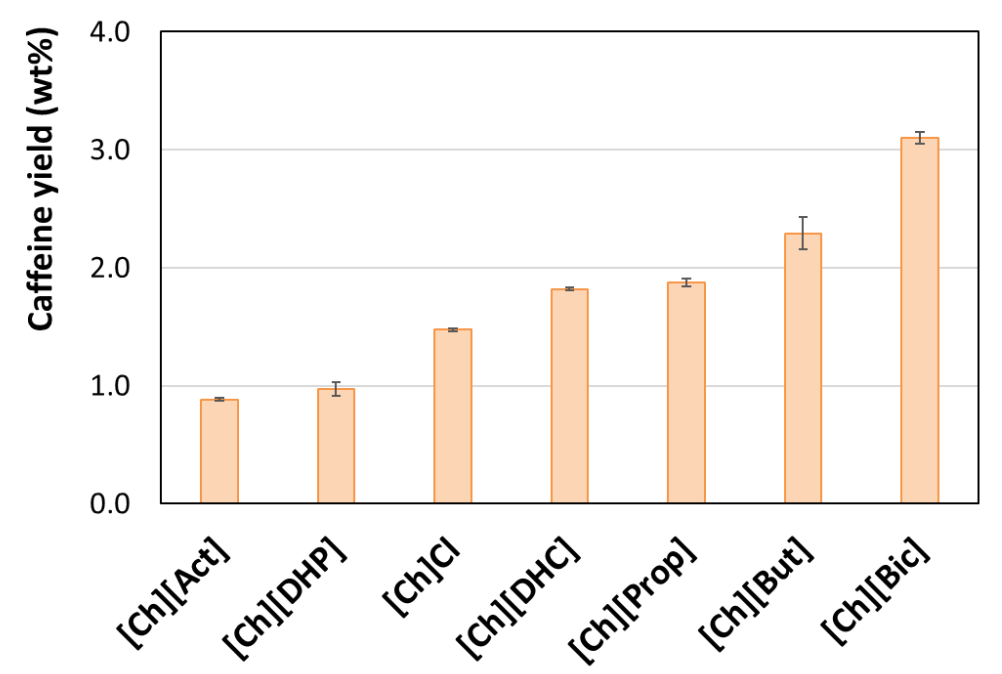

Figure 3. Caffeine yield ( $(\mathrm{wt} \%)$ from spent coffee using aqueous solutions of several ILs (concentration of IL at $2 \mathrm{M}$, temperature at $85^{\circ} \mathrm{C}$, solid-liquid ratio of 0.1 , time of extraction of $30 \mathrm{~min}$ ).

Aqueous solutions comprising ILs with anions such as acetate $(0.88 \mathrm{wt} \%)$ and dihydrogen phosphate $(0.97 \mathrm{wt} \%)$ lead to lower extraction yields, whereas aqueous solutions with cholinium-based ILs with the butanoate $(2.29 \mathrm{wt} \%)$ and bicarbonate $(3.10 \mathrm{wt} \%)$ anions lead to better extraction yields. These results demonstrate that the $\mathrm{pH}$ of the aqueous solutions is not a significant factor influencing the caffeine extraction. For instance, and as experimentally determined, aqueous solutions of cholinium acetate present a $\mathrm{pH}$ of around 8 , while the aqueous solutions of cholinium dihydrogen phosphate have a $\mathrm{pH}$ approximately of 4 , with both ILs presenting a similar ability to extract caffeine. These results are in agreement with the fact that caffeine structure does not suffer speciation within the $\mathrm{pH}$ range afforded by the investigated ILs, the dissociation constants $\left(\mathrm{p} K_{\mathrm{a}}\right)$ of caffeine being $\mathrm{p} K_{\mathrm{a} 1}=0.12$ and $\mathrm{p} K_{\mathrm{a} 2}=10.5[36,37]$. On the other hand, aqueous solutions of cholinium chloride $(1.47 \mathrm{wt} \%)$, cholinium dihydrogen citrate $(1.82 \mathrm{wt} \%)$ and cholinium propanoate $(1.88 \mathrm{wt} \%)$ reveal an intermediate ability to extract caffeine. Moreover, for the series of ILs with anions derived from carboxylic acids, the extraction yield of caffeine increases with the alkyl side chain of the IL anion ([Ch][Act $]<[\mathrm{Ch}][$ Prop] $<[\mathrm{Ch}][$ But] $)$. These results suggest that dispersive-type interactions between the ILs anions and caffeine play a crucial role. On the other hand, ILs comprising anions with higher hydrogen-bond basicity, i.e., chloride and acetate, are among the ones that lead to lower extraction yields. However, if we analyze the inclusion of a hydroxyl group in the IL anion, as is the case of bicarbonate acting as a stronger hydrogen bond donor, there is a significant increase in the caffeine yield.

In general, caffeine extraction yields ranging from $0.88 \mathrm{wt} \%$ to $3.10 \mathrm{wt} \%$ were obtained, thus showing that the introduction of ILs can lead to lower or higher values than those obtained with pure water $(1.50 \mathrm{wt} \%)$, supporting the designer solvents nature of ILs. The best IL for the extraction of caffeine is [Ch][Bic], as it is also the compound with the lowest ecotoxicity among the studied ones [32], which is a valuable feature when considering the environmental impact of the developed process.

\subsection{Optimization of the Operating Conditions Using Ionic Liquid Aqueous Solutions}

After identifying the best IL for the caffeine extraction from SCGs, [Ch][Bic], a factorial planning $2^{3}$ was applied to the respective aqueous solutions to optimize the operating conditions. The variables investigated correspond to the solid-liquid ratio, the IL concentration and the extraction temperature. The influence of the three variables on the extraction yields of caffeine is illustrated in Figure 4. All statistical analyses are provided in the Supplementary (Table S5, Figures S3 and S4). The $\mathrm{r}^{2}$ value obtained was 0.971 and the average relative 
deviation between the model results and the experimental data was $0.10 \%$, supporting the good description of the experimental results by the statistical model developed.

(a)

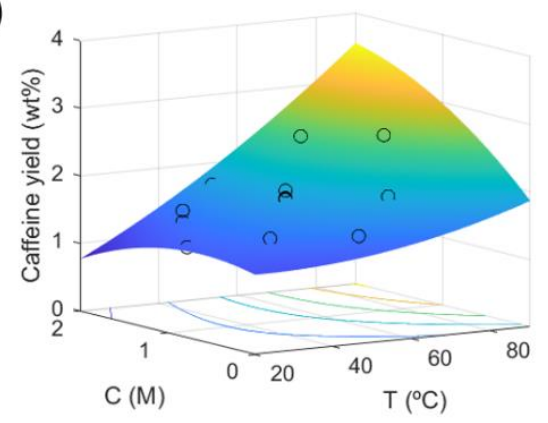

(b)

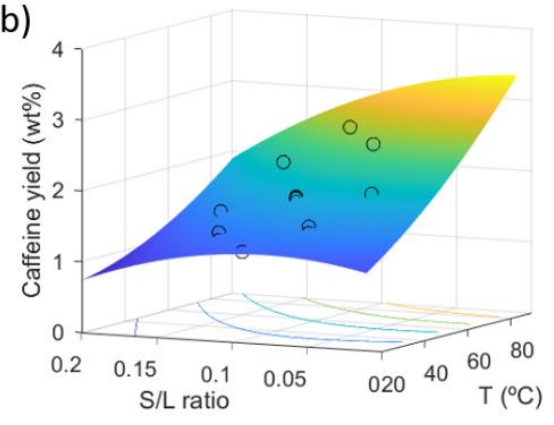

(c)

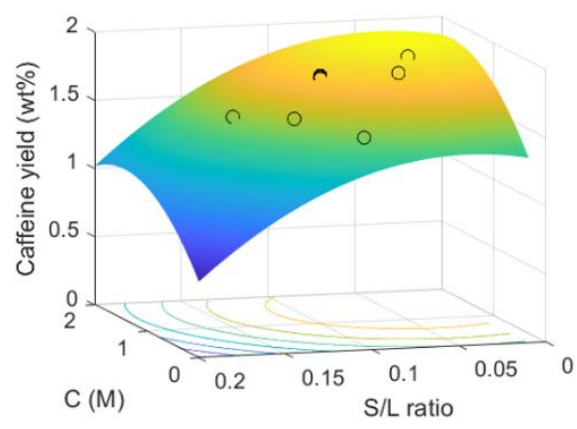

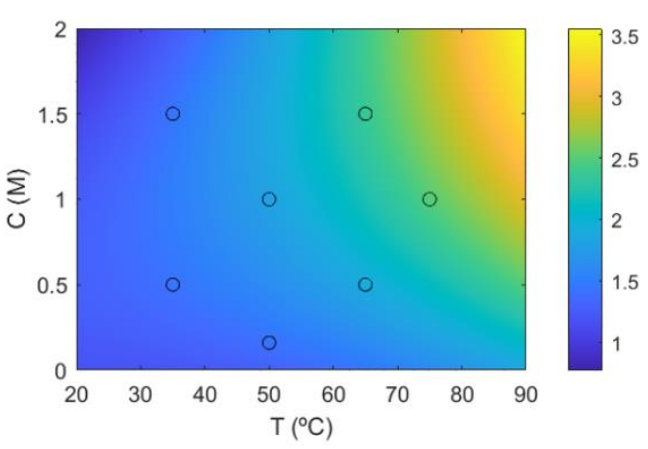
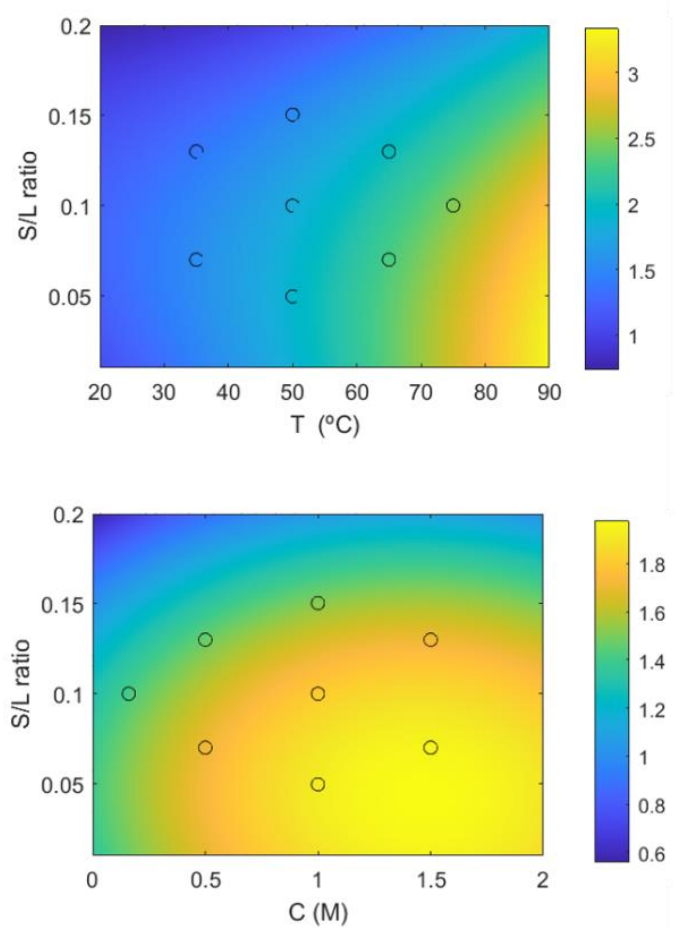

Figure 4. Response surface plots (left) and contour plots (right) for the caffeine yields from SCGs using aqueous solutions of [Ch][Bic], during $30 \mathrm{~min}$ of extraction, with the combined effects of (a) temperature and IL concentration; (b) temperature and solid-liquid ratio; (c) and solid-liquid ratio and IL concentration.

According to the statistical analysis provided in the Supplementary Materials (Pareto chart, Figure S3) and the data depicted in Figure 4, the most significant parameters in the caffeine extraction process are temperature (T), IL concentration $(C)$, solid-liquid ratio $(R)$ and the combined effects of temperature-IL concentration and the quadratic term of IL concentration ( $p$-value $<0.05)$. The model expressing the relationship between significant parameters and the global function for the extraction of caffeine using [Ch][Bic] aqueous solutions is described according to Equation (3):

$$
\text { Caffeine yield }(w t \%)=0.348 \mathrm{~T}+0.122 \mathrm{C}-0.112 \mathrm{R}+0.112 \mathrm{TC}-0.0673 \mathrm{C}^{2}
$$

The caffeine extraction increases with an increase in temperatures, particularly at temperatures higher than $80^{\circ} \mathrm{C}$. These results can be explained by the fact that an increase in temperature contributes to a decrease in the IL aqueous solution viscosity, thus favoring mass transfer, and to an enhanced swelling ability. Furthermore, higher extraction yields were obtained at IL concentrations higher than $1 \mathrm{M}$; however, only up to a maximum 
concentration. Figure 4 shows a region of maximum extraction yield at moderate IL concentrations (around $1.5 \mathrm{M}$ ). On the other hand, higher extraction yields are obtained when the solid-liquid (biomass-solvent) ratio is low, while the caffeine extraction yield significantly increases for values below 0.15 . Overall, the optimal conditions (temperature of $80{ }^{\circ} \mathrm{C}$, solid-liquid ratio of 0.05 and IL concentration of $1.5 \mathrm{M}$ ) allow an experimental extraction yield of caffeine of $3.29 \mathrm{wt} \%$, whereas the mathematical model corresponds to a value of $3.16 \mathrm{wt} \%$. This result is slightly higher than that obtained in the previous IL molecular structure screening $(3.10 \mathrm{wt} \%)$, being achieved with a lower temperature and a lower IL concentration.

The desirable region to achieve high caffeine yields using water as solvent (Figure 2) corresponds to a temperature of $85^{\circ} \mathrm{C}$ and solid-liquid ratio of 0.1 , leading to a caffeine extraction yield of $1.50 \mathrm{wt} \%$. On the other hand, using aqueous solutions of ILs, high caffeine extraction yields (Figure 4 ) are obtained at $80^{\circ} \mathrm{C}$, a solid-liquid ratio of 0.05 and an IL concentration of $1.5 \mathrm{M}$, resulting in a caffeine extraction yield of $3.29 \mathrm{wt} \%$. Furthermore, and contrary to what happens when using water, the interactions between the factors are important for obtaining a high extraction yield of caffeine when using IL aqueous solutions. In summary, the presence of an IL in the solvent made it possible to double the yield of caffeine extracted from SCGs.

The extraction of caffeine from the same SCG samples using common organic solvents was carried out, allowing to directly compare the results obtained with the traditional method (Soxhlet) and the IL aqueous solutions. The caffeine extraction yields obtained by soxhlet extraction with organic solvents during $420 \mathrm{~min}$ correspond to $0.24 \mathrm{wt} \%, 0.56 \mathrm{wt} \%$, $0.59 \mathrm{wt} \%$, and $1.59 \mathrm{wt} \%$ with petroleum ether, n-hexane, dichloromethane and ethanol, respectively. Although significantly lower than those achieved with aqueous solutions of $\mathrm{IL}$, these values are in agreement with the literature results. Bravo et al. [38] performed the soxhlet extraction of caffeine from SGCs using petroleum ether for $3 \mathrm{~h}$, at $60^{\circ} \mathrm{C}$ and a solidliquid ratio of 0.09 , obtaining yields of $0.359 \mathrm{wt} \%$ for Arabica and $0.809 \mathrm{wt} \%$ for Robusta SGCs. Panusa et al. [6] obtained an extract with $0.600 \mathrm{wt} \%$ of caffeine using a mixture of ethanol/water $(60: 40)(v / v)$ at $60{ }^{\circ} \mathrm{C}$, a solid-liquid ratio of 0.03 and during $30 \mathrm{~min}$ of extraction. These results suggest that the extraction of caffeine by soxhlet extraction using organic solvents, even for a long time, is significantly less efficient when compared to the performance displayed by IL aqueous solutions.

FTIR spectra of the original feedstock and after extraction were acquired to investigate changes in the chemical structure of SCGs, whose results are depicted in Figure S5 in the Supplementary. The FTIR of standard caffeine is also included. The infrared spectrum of caffeine displays two characteristic bands, corresponding to the carbonyl $(\mathrm{C}=\mathrm{O})$ vibration frequency at circa 1655 and $1700 \mathrm{~cm}^{-1}$. Interestingly, the high relative strength band at $1655 \mathrm{~cm}^{-1}$, indicative of caffeine, is seen in the spectrum of the SCG sample before extraction, yet it is not visible in the spectra of the SCGs after the extraction procedures and that can be associated with the extraction of caffeine by the IL-water solvent. On the other hand, it seems that the carbohydrate fraction in SCGs was not significantly dissolved by the aqueous solution of [Ch][Bic], since the bending vibrational modes of the carbohydrates (bands in the region $900-1153 \mathrm{~cm}^{-1}$ are assigned to $\mathrm{C}-\mathrm{O}$ and $\mathrm{C}-\mathrm{C}$ stretching modes, and in the region 1400-1199 $\mathrm{cm}^{-1}$ are assigned to $\mathrm{O}-\mathrm{C}-\mathrm{H}, \mathrm{C}-\mathrm{C}-\mathrm{H}$ and $\left.\mathrm{C}-\mathrm{O}-\mathrm{H}\right)$ did not suffer significant modifications. Furthermore, it should be remarked that the use of aqueous solutions of ILs allows a more selective extraction of low molecular weight compounds than pure ILs, as demonstrated in the literature in the extraction of other high-value compounds and using a wide diversity of ILs [10].

To ascertain whether the total amount of caffeine present in SGCs was extracted in a single extraction step, as well as to appraise the total amount of caffeine present in the biomass samples, the same biomass was subjected to the optimum operational conditions with three sequential extractions using fresh aqueous solutions of [Ch]Bic] at $1.5 \mathrm{M}$. The results obtained are shown in Figure 5. Negligible contents of caffeine were extracted in the second and third cycles with fresh IL aqueous solutions, with the first extraction being 
enough to extract almost all caffeine (3.29 $\mathrm{wt} \%$ ) present in SGCs, in which the total amount of caffeine was found to be $3.30 \pm 0.03 \mathrm{wt} \%$.

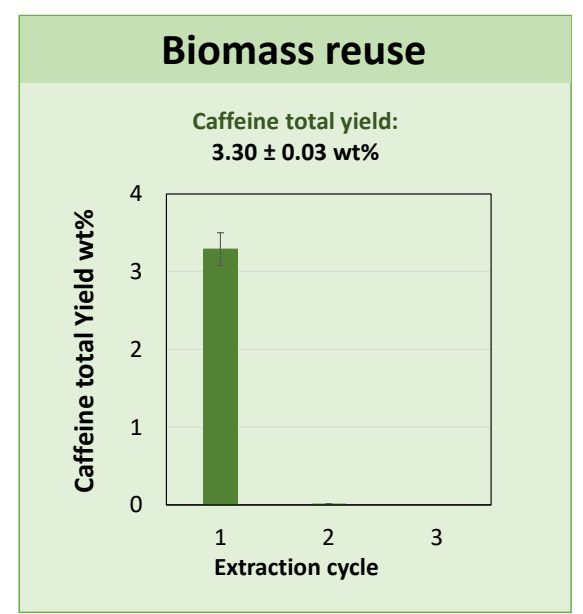

(a)

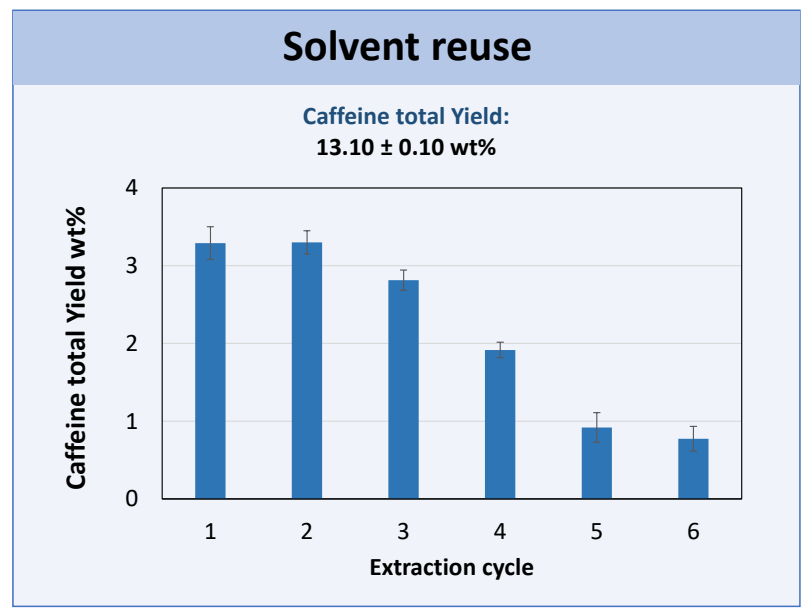

(b)

Figure 5. Caffeine extraction yields from SCGs with the (a) biomass and (b) solvent reuse under the optimized operating conditions.

With the goal of maximizing the cost-efficiency and sustainability of the developed method, the same IL aqueous solution was applied to extract caffeine from fresh SCGs at the optimum operating conditions for six consecutive cycles. The results obtained are shown in Figure 5. After six cycles of extraction, the caffeine total yield in the IL aqueous solution increased from 3.29 to $13.10 \mathrm{wt} \%$, corresponding to an increase of the caffeine concentration in the solvent from 1.74 to $6.94 \mathrm{~g} / \mathrm{L}$. The caffeine saturation at the same temperature in the IL aqueous solution, as determined by us with standard caffeine, was $78.8 \mathrm{~g} / \mathrm{L}$, meaning that the IL aqueous solution was not saturated in caffeine. Taking into account that the extraction yield of caffeine $(\mathrm{wt} \%)$ is defined as the weight of caffeine present in the extract divided by the total weight of dried SCGs, the maximum value of caffeine solubility that can be obtained in each cycle is of $3.30 \mathrm{~g} / \mathrm{L}$. Given the decrease in the extraction yield along the cycles, that other low molecular compounds may be extracted, and that there are solvent losses related to the solvent adsorption to the biomass, it is not cost-effective to reuse the solvent indefinitely. The solvent reuse seems feasible for three cycles, with no significant losses on the caffeine extraction yield.

There is evidence in the literature of the potential of extracts of spent coffee to reduce intracellular reactive oxygen species formation induced by hydrogen peroxide in $\mathrm{HaCaT}$ cells, thus reinforcing their antioxidant activity at intracellular levels [39]. Furthermore, these extracts have been shown to display free-radical scavenging activity, ABTS freeradical scavenging activity and tyrosinase inhibition capacity [40]. These findings support the potential of SCG extracts to be applied in different food, cosmetic and nutraceutical products. Envisioning these possible applications, and with the goal of guaranteeing the presence of $[\mathrm{Ch}] \mathrm{Cl}$ that is already used in animal feed (pigs, poultry, ruminants and horses, pets and fish) $[33,41]$ and cosmetic products [42,43], the aqueous solutions of [Ch][Bic] enriched in caffeine were subjected to equimolar titration with hydrochloric acid. The success of the reaction to convert the [Ch][Bic] into [Ch]Cl was verified by FTIR and ${ }^{13} \mathrm{C}$ NMR spectra (Figures S6 and S7 in the Supplementary Materials), confirming the presence of an extract containing caffeine and $[\mathrm{Ch}] \mathrm{Cl}$.

\section{Conclusions}

In this work, two factorial planning assays were investigated to optimize the operating conditions to extract caffeine from SGCs using water and aqueous solutions of ILs, while foreseeing this waste valorization. A first screening of the IL chemical structure made it 
possible to identify cholinium bicarbonate as the IL with the best performance to extract caffeine from SCGs. By the analysis of the data obtained through factorial planning using ILs aqueous solutions, it was found that temperature is the most significant parameter, followed by the concentration of IL and the solid-liquid ratio, while for water the most significant parameters are temperature and the solid-liquid ratio. In both factorial planning assays, it was demonstrated that higher temperatures and lower solid-liquid ratio favor caffeine extraction, as expected. Moreover, moderate concentrations of ILs lead to higher extraction yields, which is probably due to mass transfer limitations and viscosity of solutions with higher IL contents.

At the optimum operating conditions, water makes it possible to extract $1.50 \mathrm{wt} \%$ of caffeine, whereas the aqueous solution of cholinium bicarbonate at $1.5 \mathrm{M}$ provides a caffeine extraction yield of $3.29 \mathrm{wt} \%$. These values are significantly higher than those obtained by soxhlet extraction with molecular organic solvents, namely $0.24 \mathrm{wt} \%, 0.56 \mathrm{wt} \%$, $0.59 \mathrm{wt} \%$, and $1.59 \mathrm{wt} \%$ with petroleum ether, n-hexane, dichloromethane and ethanol, respectively. Additional experiments carried out with three consecutive fresh IL aqueous solutions and the same biomass make it possible to demonstrate that caffeine is completely extracted in the first cycle of extraction with cholinium bicarbonate aqueous solutions at the optimal conditions $\left(1.5 \mathrm{M}, 80^{\circ} \mathrm{C}\right.$, biomass-solvent ratio of 0.05$)$. To appraise the solvent saturation and try to improve the sustainability of the proposed extraction process, the same IL aqueous solution was consecutively applied to extract caffeine from six fresh biomass samples, with the extraction yield increasing from 3.29 to $13.10 \mathrm{wt} \%$. Among the studied ILs, cholinium bicarbonate presented the highest extraction performance and the lowest ecotoxicity, reinforcing its use in the extraction process. However, envisioning the IL-caffeine extract application in food, cosmetic and nutraceutical products, the cholinium bicarbonate was finally converted to cholinium chloride by titration with hydrochloric acid.

Supplementary Materials: The following are available online at https: / www.mdpi.com/article / 10.3390/su13137509/s1, Figure S1: Pareto chart, using water as solvent. $\mathrm{r}^{2}=0.904$; adj-r ${ }^{2}=0.817$; $p$-value $=0.000528 . \mathrm{T}$-temperature, $\mathrm{R}$-solid-liquid ratio and $\mathrm{t}$-time. Figure S2: Predict vs. observed values of caffeine yield ( $\mathrm{wt} \%$ ) using water as solvent. Figure S3: Pareto chart, using [Ch][Bic] as solvent. $\mathrm{r}^{2}=0.9713$; adj- $\mathrm{r}^{2}=0.946 ; p$-value $=0.000002$. $\mathrm{T}$-temperature, $\mathrm{R}$-solid-liquid ratio and C-concentration of IL. Figure S4: Predict vs. observed values of caffeine yield (wt $\%$ ) using [Ch][Bic] as solvent. Figure S5: FTIR spectra of caffeine, SCGs sample before extraction, and SCGs samples after extraction using aqueous solution of [Ch][Bic] under the optimized operational conditions. Figure S6: FTIR spectra corresponding to the pure ionic liquids, [Ch][Bic] and [Ch]Cl; and the extract obtained after six successive cycles, before and after addition of the $\mathrm{HCl}$ solution at $2 \mathrm{M}$. Figure S7: ${ }^{13} \mathrm{C}$ NMR spectra of the pure ionic liquids, [Ch][Bic] and [Ch]Cl; and the extract obtained after six successive cycles, before and after addition of the $\mathrm{HCl}$ solution at $2 \mathrm{M}$. Table S1: $2^{3}$ factorial planning. Table S2: Coded levels of independents variables used in the first factorial planning, using water as solvent. Table S3: Coded levels of independents variables used in the second factorial planning, using [Ch][Bic] as solvent. Table S4: Experimental data and response surface predicted values of the factorial planning, using water as solvent. Table S5: Experimental data and response surface predicted values of the factorial planning, using [Ch][Bic] as solvent.

Author Contributions: Conceptualization, J.A.P.C. and M.G.F.; data curation, A.M.F. and H.M.D.G.; writing—original draft preparation, A.M.F.; writing—review and editing, A.M.F., J.A.P.C. and M.G.F.; funding acquisition, J.A.P.C. and M.G.F. All authors have read and agreed to the published version of the manuscript.

Funding: This work was developed within the scope of the project CICECO-Aveiro Institute of Materials, UIDB/50011/2020 and UIDP/50011/2020, financed by national funds through the Portuguese Foundation for Science and Technology/MCTES.

Institutional Review Board Statement: Not applicable.

Informed Consent Statement: Not applicable.

Data Availability Statement: Data produced and processed in this study are included in the published article. Datasets can be acquired from the corresponding author for appropriate purposes. 
Conflicts of Interest: The authors declare no conflict of interest.

\section{References}

1. Njoroge, J.M.; Agwanda, C.O.; Kingori, P.N.; Karanja, A.M.; Gathaara, M.P.H. Handbook of Industrial Crops; Peter, K., Chopra, V., Eds.; CRC Press: Boca Raton, FL, USA, 2005; Volume Coffee.

2. Leifa, F.; Pandey, A.; Soccol, C.R. Solid state cultivation-An efficient method to use toxic agro-industrial residues. J. Basic Microbiol. 2000, 40, 187-197. [CrossRef]

3. Esquivel, P.; Jiménez, V.M. Functional properties of coffee and coffee by-products. Int. Food Res. J. 2012, 46, 488-495. [CrossRef]

4. Cruz, R.; Cardoso, M.M.; Fernandes, L.; Oliveira, M.; Mendes, E.; Baptista, P.; Morais, S.; Casal, S. Espresso Coffee Residues: A Valuable Source of Unextracted Compounds. J. Agric. Food Chem. 2012, 60, 7777-7784. [CrossRef] [PubMed]

5. Yen, W.-J.; Wang, B.-S.; Chang, L.-W.; Duh, P.-D. Antioxidant Properties of Roasted Coffee Residues. J. Agric. Food Chem. 2005, 53, 2658-2663. [CrossRef]

6. Panusa, A.; Zuorro, A.; Lavecchia, R.; Marrosu, G.; Petrucci, R. Recovery of natural antioxidants from spent coffee grounds. J. Agric. Food Chem. 2013, 61, 4162-4168. [CrossRef]

7. Stanton, K.; Tibazarwa, C.; Certa, H.; Greggs, W.; Hillebold, D.; Jovanovich, L.; Woltering, D.; Sedlak, R. Environmental risk assessment of hydrotropes in the United States, Europe, and Australia. Environ. Assess. Manag. 2010, 6, 155-163. [CrossRef]

8. Zhang, L.; Kujawinski, D.M.; Federherr, E.; Schmidt, T.C.; Jochmann, M.A. Caffeine in Your Drink: Natural or Synthetic? Anal Chem. 2012, 84, 2805-2810. [CrossRef]

9. Pokorný, J. Are natural antioxidants better-and safer-than synthetic antioxidants? Eur. J. Lipid Sci. Technol. 2007, 109, 629-642. [CrossRef]

10. Passos, H.; Freire, M.G.; Coutinho, J.A.P. Ionic liquid solutions as extractive solvents for value-added compounds from biomass. Green Chem. 2014, 16, 4786-4815. [CrossRef]

11. Ventura, S.P.M.; Francisca, A.E.S.; Quental, M.V.; Mondal, D.; Freire, M.G.; Coutinho, J.A.P. Ionic-Liquid-Mediated Extraction and Separation Processes for Bioactive Compounds: Past, Present, and Future Trends. Chem. Rev. 2017, 117, 6984-7052. [CrossRef] [PubMed]

12. GlobeNewswire. Global Caffeine Market Is Expected to Surpass US\$23,219.0 Million by 2027, Says Coherent Market Insights (CMI). Available online: https://www.globenewswire.com/en/news-release/2021/06/07/2242849/0/en/Global-CaffeineMarket-is-expected-to-surpass-US-23-219-0-Million-by-2027-Says-Coherent-Market-Insights-CMI.html (accessed on 1 February 2021).

13. Chemat, F.; Vian, M.A.; Ravi, H.K.; Khadhraoui, B.; Hilali, S.; Perino, S.; Tixier, A.-S.F. Review of Alternative Solvents for Green Extraction of Food and Natural Products: Panorama, Principles, Applications and Prospects. Molecules 2019, 24, 3007. [CrossRef] [PubMed]

14. Chemat, F.; Vian, M.A.; Fabiano-Tixier, A.-S.; Nutrizio, M.; Režek Jambrak, A.; Munekata, P.E.S.; Lorenzo, J.M.; Barba, F.J.; Binello, A.; Cravotto, G. A review of sustainable and intensified techniques for extraction of food and natural products. Green Chem. 2020, 22, 2325-2353. [CrossRef]

15. Kim, W.J.; Kim, J.D.; Oh, S.G. Supercritical Carbon Dioxide Extraction of Caffeine from Korean Green Tea. Sep. Sci. Technol. 2007, 42, 3229-3242. [CrossRef]

16. Ramalakshmi, K.; Raghavan, B. Caffeine in coffee: Its removal. Why and how? Crit. Rev. Food Sci. Nutr. 1999, 39, 441-456. [CrossRef]

17. Clarke, R.J.; Macrae, R. Coffee: Technology; Springer: Dordrecht, The Netherlands, 1987; Volume 2, pp. 59-71.

18. Cai, C.; Li, F.; Liu, L.; Tan, Z. Deep eutectic solvents used as the green media for the efficient extraction of caffeine from Chinese dark tea. Sep. Purif. Technol. 2019, 227, 115723. [CrossRef]

19. Claudio, A.F.M.; Ferreira, A.M.; Freire, M.G.; Coutinho, J.A.P. Enhanced extraction of caffeine from guarana seeds using aqueous solutions of ionic liquids. Green Chem. 2013, 15, 2002-2010. [CrossRef]

20. Bogdanov, M.G.; Svinyarov, I.; Keremedchieva, R.; Sidjimov, A. Ionic liquid-supported solid-liquid extraction of bioactive alkaloids. I. New HPLC method for quantitative determination of glaucine in Glaucium flavum Cr. (Papaveraceae). Sep. Purif. Technol. 2012, 97, 221-227. [CrossRef]

21. Bogdanov, M.G.; Svinyarov, I. Ionic liquid-supported solid-liquid extraction of bioactive alkaloids. II. Kinetics, modeling and mechanism of glaucine extraction from Glaucium flavum Cr. (Papaveraceae). Sep. Purif. Technol. 2013, 103, 279-288. [CrossRef]

22. Svinyarov, I.; Keremedchieva, R.; Bogdanov, M.G. Ionic liquid-supported solid-liquid extraction of bioactive alkaloids. IV. New HPLC method for quantitative determination of galantamine in Leucojum aestivum L. (Amaryllidaceae). Sep. Sci. Technol. 2016, 51, 2691-2699. [CrossRef]

23. Ventura, S.P.M.; Neves, C.M.S.S.; Freire, M.G.; Marrucho, I.M.; Oliveira, J.; Coutinho, J.A.P. Evaluation of Anion Influence on the Formation and Extraction Capacity of Ionic-Liquid-Based Aqueous Biphasic Systems. J. Phys. Chem. B 2009, 113, 9304-9310. [CrossRef]

24. Docherty, K.M.; Kulpa, J.C.F. Toxicity and antimicrobial activity of imidazolium and pyridinium ionic liquids. Green Chem. 2005, 7, 185-189. [CrossRef]

25. Wiedeman, A.M.; Barr, S.I.; Green, T.J.; Xu, Z.; Innis, S.M.; Kitts, D.D. Dietary Choline Intake: Current State of Knowledge Across the Life Cycle. Nutrients 2018, 10, 1513. [CrossRef] [PubMed] 
26. Santos, J.I.; Gonçalves, A.M.M.; Pereira, J.L.; Figueiredo, B.F.H.T.; Francisca, A.E.S.; Coutinho, J.A.P.; Ventura, S.P.M.; Gonçalves, F. Environmental safety of cholinium-based ionic liquids: Assessing structure-ecotoxicity relationships. Green Chem. 2015, 17, 4657-4668. [CrossRef]

27. Meck, W.H.; Williams, C.L. Choline supplementation during prenatal development reduces proactive interference in spatial memory. Brain Res. Dev. Brain Res. 1999, 118, 51-59. [CrossRef]

28. Wang, R.; Chang, Y.; Tan, Z.; Li, F. Applications of choline amino acid ionic liquid in extraction and separation of flavonoids and pectin from ponkan peels. Sep. Sci. Technol. 2016, 51, 1093-1102. [CrossRef]

29. Neves, C.M.S.S.; Figueiredo, M.; Reis, P.M.; Sousa, A.C.A.; Cristóvão, A.C.; Fiadeiro, M.B.; Rebelo, L.P.N.; Coutinho, J.A.P.; Esperança, J.M.S.S.; Freire, M.G. Simultaneous Separation of Antioxidants and Carbohydrates From Food Wastes Using Aqueous Biphasic Systems Formed by Cholinium-Derived Ionic Liquids. Front. Chem. 2019, 7. [CrossRef]

30. Quental, M.V.; Pedro, A.Q.; Pereira, P.; Sharma, M.; Queiroz, J.A.; Coutinho, J.A.P.; Sousa, F.; Freire, M.G. Integrated ExtractionPreservation Strategies for RNA Using Biobased Ionic Liquids. ACS Sustain. Chem. Eng. 2019, 7, 9439-9448. [CrossRef]

31. Ribeiro, B.D.; Coelho, M.A.Z.; Rebelo, L.P.N.; Marrucho, I.M. Ionic Liquids as Additives for Extraction of Saponins and Polyphenols from Mate (Ilex paraguariensis) and Tea (Camellia sinensis). Ind. Eng. Chem. Res. 2013, 52, 12146-12153. [CrossRef]

32. Ventura, S.P.M.; Francisca, A.E.S.; Gonçalves, A.M.M.; Pereira, J.L.; Gonçalves, F.; Coutinho, J.A.P. Ecotoxicity analysis of cholinium-based ionic liquids to Vibrio fischeri marine bacteria. Ecotoxicol. Environ. Saf. 2014, 102, 48-54. [CrossRef] [PubMed]

33. BASF. Choline Chloride-What Your Body Needs to Form Vital Bodily Substances. Available online: https://Nutrition.Basf.com/ Global/En/Animal-Nutrition/Products/Choline-Chloride.html (accessed on 1 February 2021).

34. Pernak, J.; Syguda, A.; Mirska, I.; Pernak, A.; Nawrot, J.; Pradzyńska, A.; Griffin, S.T.; Rogers, R.D. Choline-derivative-based ionic liquids. Chem. A Eur. J. 2007, 13, 6817-6827. [CrossRef] [PubMed]

35. Muhammad, N.; Hossain, M.I.; Man, Z.; El-Harbawi, M.; Bustam, M.A.; Noaman, Y.A.; Mohamed Alitheen, N.B.; Ng, M.K.; Hefter, G.; Yin, C.-Y. Synthesis and Physical Properties of Choline Carboxylate Ionic Liquids. J. Chem. Eng. Data 2012, 57, 2191-2196. [CrossRef]

36. Pereira, J.F.B.; Magri, A.; Quental, M.V.; Gonzalez-Miquel, M.; Freire, M.G.; Coutinho, J.A.P. Alkaloids as Alternative Probes to Characterize the Relative Hydrophobicity of Aqueous Biphasic Systems. ACS Sustain. Chem. Eng. 2016, 4, 1512-1520. [CrossRef]

37. Latosińska, J.N.; Latosińska, M.; Olejniczak, G.A.; Seliger, J.; Žagar, V. Topology of the Interactions Pattern in Pharmaceutically Relevant Polymorphs of Methylxanthines (Caffeine, Theobromine, and Theophiline): Combined Experimental (1H-14N Nuclear Quadrupole Double Resonance) and Computational (DFT and Hirshfeld-Based) Study. J. Chem. Inf. Model. 2014, 54, $2570-2584$. [CrossRef] [PubMed]

38. Bravo, J.; Juániz, I.; Monente, C.; Caemmerer, B.; Kroh, L.W.; De Peña, M.P.; Cid, C. Evaluation of spent coffee obtained from the most common coffeemakers as a source of hydrophilic bioactive compounds. J. Agric. Food Chem. 2012, 60, 12565-12573. [CrossRef] [PubMed]

39. Gigliobianco, M.R.; Campisi, B.; Peregrina, D.V.; Censi, R.; Khamitova, G.; Angeloni, S.; Caprioli, G.; Zannotti, M.; Ferraro, S.; Giovannetti, R.; et al. Optimization of the Extraction from Spent Coffee Grounds Using the Desirability Approach. Antioxidants 2020, 9, 370. [CrossRef]

40. Wu, C.-T.; Agrawal, D.C.; Huang, W.-Y.; Hsu, H.-C.; Yang, S.-J.; Huang, S.-L.; Lin, Y.-S. Functionality Analysis of Spent Coffee Ground Extracts Obtained by the Hydrothermal Method. J. Chem. 2019, 2019, 4671438. [CrossRef]

41. EFSA Panel on Additives and Products or Substances used in Animal Feed (FEEDAP). Scientific Opinion on safety and efficacy of choline chloride as a feed additive for all animal species. EFSA J. 2011, 9, 2353. [CrossRef]

42. Nayak, S.; Nayak, V. Use of Partial and Complete Salts of Choline and Carboxylic Acids for the Treatment of Skin Disorders. U.S. Patent 6,120,779, 19 September 2000.

43. Becker, L.C.; Bergfeld, W.F.; Belsito, D.V.; Hill, R.A.; Klaassen, C.D.; Liebler, D.; Marks, J.G.; Shank, R.C.; Slaga, T.J.; Snyder, P.W.; et al. Safety Assessment of Trimoniums as Used in Cosmetics. Int. J. Toxicol. 2012, 31, 296S-341S. [CrossRef] 